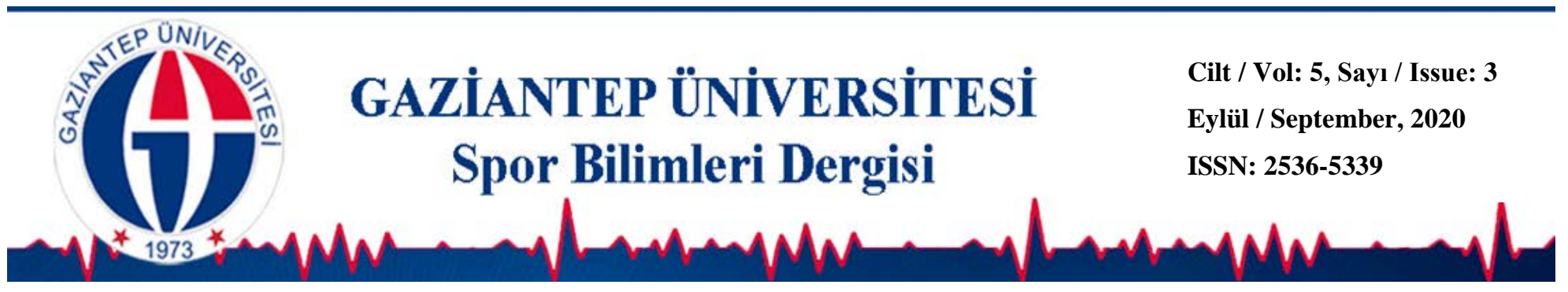

\title{
Spor Tesis Yeterliğini Belirlemeye Yönelik Bir Ölçek Geliştirme Çalışması
}

\author{
Arif ÇETIN $^{1 *}$ Aydın KARAÇAM ${ }^{2}$ (D)
}

DOI: 10.31680/gaunjss.765385

Orijinal Makale / Original Article

Geliș Tarihi / Received: 07.07.2020
Kabul Tarihi / Accepted: 05.09.2020

Öz

Bu çalışmada Türkiye koşullarına uygun olarak spor tesislerinin yeterliğini analiz eden bir ölçeğin geliştirilmesi amaçlanmıştır. Araştırmanın örneklemi, İstanbul'da spor sektöründe çalışan spor yöneticileri arasından amaçı örnekleme yöntemi ile oluşturulmuştur. Bu yöntemle araştırmaya 164 spor yöneticisi katılımış olup katılımcıların \%26,2'si (n:43) kadın ve \%73,8`i ( $n=121$ kişi) erkektir. Açıklayıcı faktör analizi (AFA) sonucunda ölçeğin tek boyut ve 12 maddeden oluştuğu tespit edilmiştir. AFA sonucunda toplam açıklanan varyansın \%50.876 olduğu görülmüş̧ür. Ölçek için cronbach alfa iç tutarlık katsayı .906 ve KMO değerinin .894 olduğu görülmüştür. Spor Tesis Yeterliği Ölçeğinin madde toplam korelasyonlarının .555 ile .835 arasında değişiklik gösterdiği görülmüştür. Ölçeğe uygulanan Doğrulayıcı Faktör Analizi (DFA) sonucunda $\chi^{2} / s d=2.425$, RMSEA $=.094$ olduğu görülmüşșur. Çalışmada elde edilen sonuçlar, STYÖ'nün spor tesislerinin yeterliğini tespit etmede kullanılabilecek geçerli ve güvenilir bir ölçme aracı olduğunu göstermiştir.

Anahtar Kelimeler: Spor tesisi, yeterlik, ölçek geliştirme

\section{The Scale Development Study to Determine of the Sports Facility Competence}

\begin{abstract}
This study aimed to develop a scale that analyses the competence of sports facilities following the conditions of Turkey. The sampling of the research was created with a purposive sampling method among sports managers working in the sports sector in Istanbul. 164 people participated in the study and 26,2 of $(n=43)$ female, $73,8 \%$ of the participants $(n=121)$ were male in the research with the method. As a result of the exploratory factor analysis (EFA), it was determined that the scale consists of one dimension and 12 items. As a consequence of EFA, the total explained variance was found to be $50.876 \%$. The Cronbach's alpha internal consistency coefficient for the scale was .906, and the KMO value was .894. Item total correlations of the Sports Facility Competence Scale (SFCS) ranged from .555 to .835. Confirmatory Factor Analysis (CFA) applied to the scale showed that $\mathrm{X}^{2} / \mathrm{sd}=2.425$, RMSEA $=.094$. The results obtained in the study showed that SFCS is a valid and reliable measurement tool that can be used to determine the adequacy of sports facilities.
\end{abstract}

Keywords: Sport facility, competence, scale development

\footnotetext{
* Sorumlu Yazar: Arif ÇETİN
}

E-mail: arifcetin1985@yahoo.com 


\section{Giriş}

Spor tesisi operasyon yönetimini etkin bir şekilde anlamak için tesis yönetimi ve operasyon yönetiminin iki temel kavramını anlamak önemlidir. Tesis yönetimi, ticari ve kâr amacı gütmeyen yapıların planlaması, bakım onarımını ve işletmesini kapsayan bir terimdir (Schwarz ve ark., 2015). Spor tesislerinin planlanması, bireylerin spora katılım davranışlarını etkileyen önemli bir unsur olarak kabul edilmektedir (Nicholson ve ark., 2011). Spor tesisleri inşa etmek, birçok ülkede spor ve fiziksel aktiviteyi teşvik etmenin temel kamu araçlarından birisi olarak görülmektedir. Bu tesislerin inşası, yönetimi ve işletmesi için belirlenecek stratejiler spor ve fiziksel aktivite koşullarını anlamanın temel yapı yaşıdır (Bergsgard ve ark., 2017). Çünkü, ekonomik tasarruf önlemleri kapsamında kamu ve yerel otoritelerin spora yaptıkları harcamalarda daha ihtiyatlı bir yol izledikleri görülmektedir (Földesi, 2014). Dolayısıyla, spor bütçelerinin büyük bir kısmı genellikle spor tesislerinin inşası ve işletilmesine ayrılmış olduğundan, maliyetleri azaltmanın yollarını belirlerken spor tesislerine büyük önem verilmektedir. Bu bakımdan karar vericiler spor tesisi yeterliğini ölçmek için göstergelerle yakından ilgilenmektedir (Hoekman ve ark., 2015).

Spor; bireysel uygunluk, eğlence ve refah gibi bireysel ihtiyaçların karşılanmasına katkıda bulunmasının yanı sıra sosyal entegrasyon, sosyalleşme ve halk sağlığı gibi faydalar da üretir. Bu nedenle spora katılımı teşvik etmek kamunun yararınadır. Birçok ülke gerek merkezi hükümetler gerekse de yerel yönetimler vasıtasıyla bireylerin fiziksel aktivite içerisinde yer almaları için spor tesisleri yatırımları yapmakta ve bu tesislerin aktif bir şekilde kullanılması için de spor projelerini hayata geçirmektedir (Hallmann ve ark., 2012). Ülkemizde ise yerel yönetimlerin gerek bünyesindeki Gençlik ve Spor Müdürlükleri yoluyla gerekse de iştirak şirketleri aracılığıyla vatandaşlarına spor hizmeti götürmektedir. Bunun en iyi örnekleri arasında ise İstanbul Büyükşehir Belediyesi Spor İstanbul gelmektedir. Şirketin bünyesinde işlettiği 50 spor tesisinde yılda 6,7 milyon seans hizmet vermekte ve bu seanslardan 660 bin birey yararlanmaktadır.

Spor tesislerinin yeterliği ve erişilebilirliği bireylerin spor faaliyetlerine katılıp katılmama kararını etkileyebilir (Ries ve ark., 2011). Başka bir deyişle, inşa edilecek tesislerde fiziksel aktivite ortamlarının halkın katılımına uygun dizayn edilmeyişi ve de erişilebilir olmayışı bireylerin spor aktivitelerine katılımını engellemektedir (Guo ve ark., 2014). Bununla ilgili olarak, yapılan araştırmalarda, spor tesislerinin uygunluğu 
ve de çekiciliği bireylerin fiziksel aktiviteye katılım davranışlarında doğrudan ilişkili olduğu tespit edilmiştir (Bergsgard ve ark., 2017; Sugiyama ve ark., 2010).

Modern yaşam ile birlikte spor tesisleri sadece spor etkinlikleri bağlamında ele alınmamaktadır. Bu durum, tesis özelliklerini, kapasitelerini ve kullanım amaçlarını değiştirmekte ve yalnızca profesyonel spor etkinliğinin organize edileceği spor tesisleri üretilmemektedir. Bu bağlamda, spor tesisleri kullanıcı gruplarının yaşlarına, aktivite düzeylerine, spor alanlarının özelliklerine, spor branşlarına katılım sayısına, kullanıcı türüne, yapılış amacına, yapıldığı yere ve yapıldığı standartlara göre gruplandırılabilir (Fried, 2010).

Spor tesislerinin planlamasına ise fizibilite çalışması ile başlanmalıdır. Fizibilite, bir organizasyonun devam eden stratejik planlamasının temelini oluşturmaktadır. Bu bakış açısıyla, fizibilite çalışması sırasında gerçekleştirilen faaliyetler ve analizler bir defalık fikirler olmayıp, sürdürülebilirliğin güvencesi için temel analitik tekniklerdir. Bununla birlikte, bir fizibilite çalışmasında olumlu bir sonuç başarının garantisi değildir. Bu sadece bir risk beyanıdır çıktılar ne kadar olumlu olursa, riskin de bir o kadar düşük olması beklenir. Fizibilite aşamasından sonra ise tasarım ve yapım sürecine geçilir. Bu sürecin genel yaklaşımı ise şu şekildedir (Westerbeek ve ark., 2006):

- Talep, ihtiyaç ve bütçe araştırması yapmak

- Stratejik bir plan geliştirmek

- Tesis yerinin seçimini yapmak

- Tasarım ve tesis özetinin oluşturmak

- Kapasite kullanımını belirlemek

- Açık-kapalı spor alanlarını belirlemek

- Spora özgü düzenlemeler ve teknik özellikleri belirlemek

- Verilecek hizmetleri belirlemek

- Mimari kimliği belirlemek

- İnşa ekibini belirlemek

- Inşaat sürecinin başlamak

- Operasyon özet raporunun oluşturmak

Dolayısıyla, spor tesislerinin planlaması da hem karar vericiler hem de uygulayıcılar için büyük bir zorluktur, çünkü birçok insanın ihtiyaçlarını karşılayacak çok amaçlı bir tesis yapılması gerekir (Stinnett ve Gibson, 2016). 
Erişilebilir, güvenli, kompakt, işletme maliyetlerinin minimum seviyede tutulduğu, ekonomik ömrü uzun ve rekreatif amaçlarla kullanılan tesisler kamunun ve özellikle de yerel yönetimlerin üzerinde önemle durulması gereken bir konu olarak karşımıza çıkmaktadır. Bu noktada, ülkemizde birçok şehirde gerek büyükşehir gerekse de ilçe belediyeleri marifetleriyle birçok tesis yatırımı gerçekleştirilmektedir. Bu da tesislerin planlama ve işletme performanslarının ne düzeyde olduğu sorusunu akla getirmektedir. Var olan bu tesislerin yeterliğinin belirlenebilmesi için öncelikle bir yeterlilik ölçeğine intiyaç duyulmaktadır. Türkiye koşullarına uygun olarak ülkemizde spor tesislerinin yeterliğini analiz eden bir ölçeğin geliştirilmesi amaçlanmıştır.

\section{Yöntem}

\section{Evren ve Örneklem}

Araştırmanın örneklemi, İstanbul'da spor sektöründe çalışan spor yöneticileri arasından amaçlı örnekleme yöntemi ile oluşturulmuştur. Bu yöntemle araştırmaya 164 kişi katılmış olup katılımcıların \%26.2’si ( $n=43)$ kadın ve \%73.8`i ( $n=121$ kişi) erkek; \%79.9'u ( $n=131)$ bekar ve \%20.1'i $(n=33)$ evlidir. Grubun yaş ortalaması 40 (ss:7.19) olup; katılımcıların \%68,9'u ( $n=113)$ lisans mezunudur. Bununla birlikte katılımcıların iş hayatındaki ortalama çalışma sureler 14 yıl (ss: 7.04) olarak tespit edilmiştir.

\section{Veri Toplama Araçları}

Araştırmada, spor yöneticilerinden nicel veriler elde edilmiştir. Bu verilerin toplanması amacıyla İBB Spor İstanbul tarafından işletilen spor tesislerinde görev alan tesis amir ve amir yardımcılarına uygulanan "Spor Tesis Yeterliği Ölçeği" araştırmacılar tarafından geliştirilmiştir.

\section{Verilerin Toplanması}

İB Spor İstanbul tesis amir ve amir yardımcılarından pozisyonundaki 5'er spor yöneticisi ile görevli olduğu tesisle ilgili görüşmeler yapılmıştır. Bu spor yöneticilerin görüşleri ve literatüre dayalı olarak 22 maddelik soru havuzu oluşturulmuştur. Oluşturulan soru havuzundaki soruların uzman görüşünün de alınması için alanında uzman spor yöneticisi görüşüne sunulmuş ve soru havuzu onaylanmıştır. Onayı alınan sorular, ayrıca Türkçe dil uzmanı incelemesine sunulmuş 
ve gerekli düzenlemeler gerçekleştirilmiştir. 22 maddelik ölçek 164 spor yöneticisine uygulanmıştır.

\section{Verilerin analizi}

Verilerin analizinde ölçeğin güvenirlilik düzeyinin belirlenmesi için AFA, güvenirlilik analizleri ve DFA yapılmıştır. DFA ile birlikte birçok uyum indeksine bakılır. Bu değerlerden ilki ki kare/serbestlik derecesidir. Bu değerin 2.5’ten küçük olması modelin mükemmel uyumuna (Çokluk ve ark., 2010; Doğan ve Özdamar, 2017); yaklaşık hataların karakökü (RMSEA) değerinin .06'dan küçük olması modelin mükemmel uyumuma işaret etmektedir (

\section{Bulgular}

Tablo 1. Araştırma Örnekleminin Genel Karakteristikleri

\begin{tabular}{ccc}
\hline Cinsiyet & Frekans (n) & Yüzde (\%) \\
\hline Erkek & 121 & 73.8 \\
Kadın & 43 & 26.2 \\
Toplam & 164 & 100 \\
\hline Medeni Durum & Frekans (n) & Yüzde (\%) \\
\hline Evli & 131 & 79.9 \\
Bekâr & 33 & 20.1 \\
Toplam & 164 & 100 \\
\hline
\end{tabular}

Araştırmaya katılan 164 katılımcının \%73.8`i ( $n=121$ kişi) erkek; \%26.2’si ( $n=43$ kişi) kadındır. Katılımcıların \%79.9'u (n=131) evli \%20.1'i ise bekardır.

\section{Açıklayıcı Faktör Analizi (AFA)}

Ölçekle ilgili geçerlik ve güvenirlilik sonuçlarına ilişkin veriler aşağıdaki tabloda belirtilmiştir.

Tablo 2. AFA ve Güvenirlilik Sonuçları

\begin{tabular}{cccccccc}
\hline Boyut & $\begin{array}{c}\text { Madde } \\
\text { Sayısı }\end{array}$ & KMO & $\begin{array}{c}\text { Barlett's } \\
X^{2}\end{array}$ & $\begin{array}{c}\text { Açıklanan } \\
\text { Varyans \% }\end{array}$ & En düşük & En Yüksek & $\begin{array}{c}\text { Cronbach's } \\
\text { Alpha }\end{array}$ \\
\hline Yeterlilik & 12 & .894 & $\begin{array}{c}1033.752 \\
p<.001\end{array}$ & 50.876 & 0.555 & 0.835 & .906 \\
\hline
\end{tabular}


Çetin, A. ve karaçam, A. (2020). Spor Tesis Yeterliğini Belirlemeye Yönelik Bir Ölçek Geliştirme Çalışması. Gaziantep Üniversitesi Spor Bilimleri Dergisi, 5(3), 299-309.

Spor tesis yeterliği ölçeğinin geçerlilik ve güvenirlilik çalışmaları neticesinde ölçeğin KMO değerinin .906, Barlett's katsayının $1033.752(p<.001)$ olarak tespit edilmiştir. Bu değerler ölçeğin faktör analizine uygun olduğuna işaret etmektedir. Maddelere uygulanan AFA sonuçlarına göre bazı ölçek maddelerin faktör yüklerinin $(1,2,3,4,11,12,15,16,19,21)$ uygun bir şekilde dağılım göstermediği tespit edilmiş olup bu maddeler ölçekten çıkarılmışıı. Kalan 12 maddeye uygulanan AFA sonuçlarının temelinde $5,6,7,8,9,10,13,14,17,18,20,22$ tek boyut altında toplanmıştır. Tek boyutlu ölçeğin faktör yük değerlerinin ise .555 ile .835 arasında değiştiği, Cronbach's Alpha değerinin ise .906 olduğu bulunmuştur. Ayrıca, ölçeğin toplam varyansın \%50.876'sını açıkladığı görülmüştür.

Tablo 3. Faktör Yükleri

\begin{tabular}{ll} 
Ölçek Maddeleri & Faktör \\
& Yükleri \\
\hline
\end{tabular}

1. Tesisin tüm birimleri (spor alanları, tribün kapasiteleri, koridor genişlikleri, .754 otopark, elektronik aksamlar) ulusal ve uluslararası standartlara uygun olarak planlanmıştır.

2. Tesis, enerji tasarrufu ve verimliliği ile ilgili donanıma sahip bir şekilde inşa .668 edilmiştir.

3. Tesisin anlık elektrik, yakıt ve ısıtma tüketimini (havuz ortamı, havuz suyu .582 sıcaklığı ve ph değeri vb.) anlık görebileceği bir sisteme sahiptir.

4. Spor alanlarında (spor salonları ve yüzme havuzları) aynı anda birden fazla spor faaliyeti gerçekleştirilecek şekilde inşa edilmiş ve standartlara uygun olarak inşa edilmiştir.

5. Soyunma odaları, spor müsabakaları (eğitim ve müsabakalar) göz önünde .785 bulunularak inşa edilmiştir.

6. Soyunma odaları spor eğitimleri göz önünde bulunularak inşa edilmiştir $\quad .769$

7. Tesis; şimdiki ve gelecekteki intiyaçları karşılayacak bir şekilde inşa edilmiştir. $\quad$. $\quad$ 832

8. Tesis, işletme maliyetlerini minimum seviyede olacak şekilde inşa edilmiştir. $\quad$. $\quad$ 672

9. Tesis, kullanıcı intiyaçlarını göz önünde bulundurarak inşa edilmiştir. $\quad 835$

10. Tesis projesi, potansiyel kullanıcı grupların ve alanında uzman profesyonellerin $\quad .831$ katılımıyla planlanmıştır.

11. Spor seansları, sonrası müşterilerin dinlenebileceği ve vakit geçirebileceği .596 sosyal alanlar yeterlidir.

12. Spor salonlarının zemini birçok farklı spor dalının yapılmasına uygundur

.590 


\section{Doğrulayıcı Faktör Analizi (DFA) Sonuçları}

Açıklayıcı faktör analizi sonunda ortaya çıkan 12 maddeden oluşan tek boyutlu yapının toplanan veriler için ne ölçüde uygun olduğunu belirlemek amacıyla DFA analizi yapılmıştır. Ölçekle ilgili yapılan DFA sonuçları ise Tablo 3'de yer almaktadır.

Tablo 4. DFA Sonuçları

\begin{tabular}{cccl}
\hline $\mathrm{X}^{2}$ & sd & $\left(\mathrm{x}^{2} / \mathrm{sd}\right)$ & RMSEA \\
\hline 126,101 & 52 & 2,425 &, 094 \\
\hline
\end{tabular}

Ölçeğin DFA sonuçlarına ilişkin tablo incelendiğinde ki-kare $\left(\mathrm{X}^{2}\right)$ değerinin 126,101; serbestlik derecesinin (sd) 52 ve ki-kare/serbestlik derecesinin ise 2.425 olduğunu göstermektedir. Bu veriler ışığında ölçeğin açıklayıcı faktör analizini desteklediği göstermektedir. Ayrıca RMSEA değerinin .094 olduğu tespit edilmiştir. Bu değerler modelin kabul edilebilir olduğunu gösterir (Doğan ve Özdamar, 2017).

Şekil 1'de ise ölçeğin her bir maddesinin gizil bağımlı değişken üzerindeki tahmin miktarları ve korelasyon katsayıları verilmiştir. Tek boyutlu modelde korelasyon kat sayılarının .45 ile .85 arasında değiştiği görülmektedir. Bu verilere göre maddeler arasındaki korelasyon katsayılarının kabul edilebilir bir düzeyde olduğu söylenebilir.

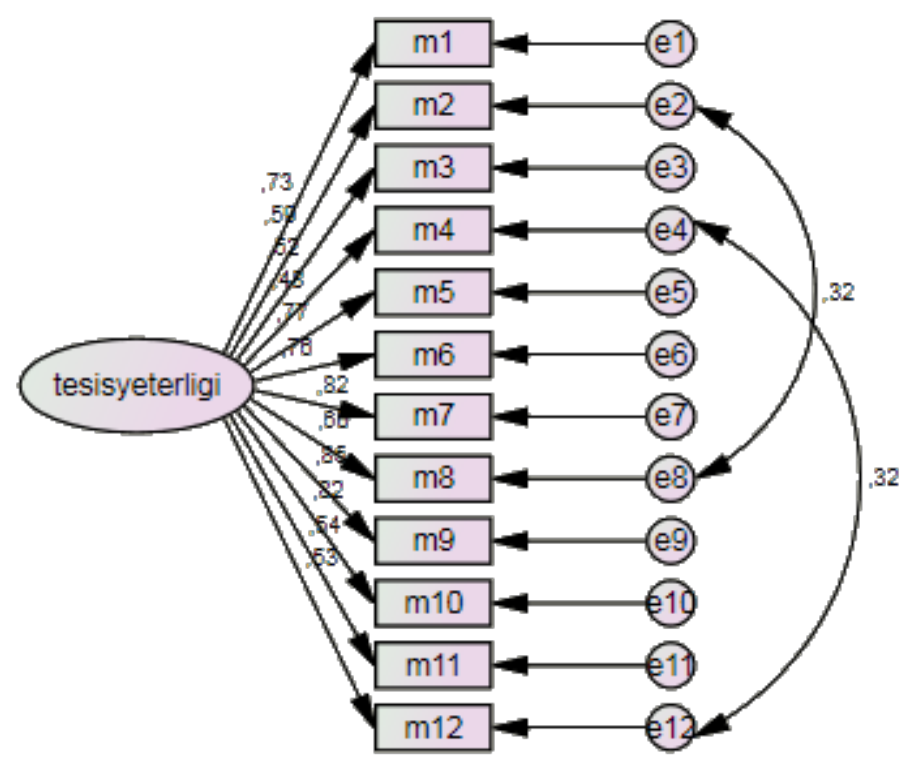

Şekil 1. Spor Tesis Yeterliği Ölçeği'nin Yol Diyagramı 


\section{Tartışma ve Sonuç}

Bu araştırmada Türkiye koşullarına uygun olarak ülkemizde halkın kullanımına açık olan spor tesislerinin yeterliğini analiz eden geçerli ve güvenilir bir ölçeğin geliştirilmesi amaçlanmıştır. Bu amaçla toplanan 22 maddeden oluşan verilere uygulanan AFA neticesinde 10 madde hiçbir faktör altında yer almadığı tespit edilmiştir. Kalan 12 madde için yapılan analizler sonucunda tek boyuttan oluşan Spor Tesisi Yeterliği ölçeğinin açıkladığı varyans \%50.876'dır. Tek faktörlü ölçeklerde açıklanan varyansın \%30 ve daha fazla olması yeterli görülmektedir (Büyüköztürk, 2010; Çokluk ve ark., 2010). Bu bulgu ölçeğin genel bir faktöre sahip olduğunu da göstermektedir. Ölçeğin faktör yükleri ise .555 ile .835 arasında değişmektedir. Faktör yük değerinin .45 ya da daha yüksek olması seçim için iyi bir ölçüttür. Fakat bu değerin .30'a kadar indirilebileceği belirtilmiştir (Büyüköztürk, 2010). Ölçeğin güvenirliliğini gösteren Cronbach's Alpha değerinin ise .906 olduğu tespit edilmiştir.

AFA sonunda ortaya çıkan faktör yapısının toplanan veriler için ne ölçüde uygun olduğunu belirlemek amacıyla DFA yapılmıştır. DFA daha önceden tanımlanmış ve sınırlandırımış bir yapının, bir model olarak doğrulanıp doğrulanmadığının test edildiği bir analizdir (Çokluk ve ark., 2010). Yaklaşık Hataların Ortalama Karekökü'nün (Root Mean Square Error of Approximation, RMSEA) .05'ten küçük olmasının iyi uyumu, .10'in altında olması ise kabul edilebilir bir uyum iyiliğini, ki-kare/serbestlik derecesi uyum indeksinin 5'ten küçük olması orta düzeyde, 2.5'ten küçük olması mükemmel uyumu göstermektedir (Çokluk ve ark., 2010; Kline, 2005; Schumacker ve Lomax, 2004; Şimşek, 2007; Tabachnick ve Fidell, 2007; Yılmaz ve Çelik, 2009).

Ölçeğe uygulanan DFA için uyum indeksleri incelendiğinde ki-kare değerinin serbestlik derecesine oranının (126.101/52= 2.425) 2.5'in altında mükemmel düzeyde bir değere sahip olduğu görülmüştür. Diğer uyum indeksleri incelendiğinde RMSEA $=.094$ olarak bulunmuştur. Bu değerin tamamı kabul edilebilir uyum düzeyinde olduğunu işaret etmektedir. DFA sonucunda elde edilen uyum iyiliği indeksleri incelendiğinde modelin uyumlu olduğu görülmektedir.

Ölçeğin spor tesisi yeterliği üzerindeki değişkenlerini öngörmede geçerliliği ve güvenilirliğinden yola çıkarak spor yönetimi literatürüne katkı sağladığı söylenebilir. Ülkemizde bu konuyla ilgili çalışmalar incelendiğinde genellikle tesislerin bölge dağılımları, var olan tesislerdeki spor alanlarının sayısı ve ölçüleri gibi değişkenlerin ele alındığı görülmüştür. Bu çalışma ile spor tesislerinin teknik özelliklerinin yanında 
işletme ve hizmet yönlerini de kapsamaktadır. Bunun yanında, yapılan geçmiş çalışmalar genellikle araştırmacıların kendi gözlemleri ya da tesis kullanıcıların memnuniyeti düzleminde ele alınmıştır. Yapılan bu çalışmada ise tesisleri işleten en yetkili yöneticiler arasında yer alan tesis amir ve amir yardımcıları boyutunda ele alınmıştır.

Spor Tesis Yeterliği Ölçeğinin bir takım yönetsel çıktıları bulunmaktadır. Bu çıktılar arasında ilk olarak hem kamu hem de yerel yönetim otoriteleri tarafından spor tesis projelerini hayata geçirmek için bir yönetim aracı olarak kullanılabilir. Böylelikle spor tesislerinin planlanması ile tesis inşasındaki operasyon yönetiminin optimizasyonu sağlanabilir. İkinci olarak, araştırmanın örneklemini tesis amir ve amir yardımcıları inşa edilecek ya da işletilecek spor tesislerinin talep, intiyaç, stratejik plan, tasarım ve tesis fizibilite çalışmalarında spor yöneticilerinin de görüşünün alınması gerekliliğidir.

Sonuç olarak, "Spor Tesis Yeterliği" ölçeğinin geçerlilik ve güvenirlilik sonuçları ışığında ölçeğin Türkiye koşullarına uygun olarak ülkemizdeki spor tesislerinin yeterliğini analiz etmede kullanılabilecek bir yapıda olduğu görülmüştür. Araştırmalar çerçevesinde literatürde hem profesyonel spor müsabakalarının hem de halka açık spor tesislerinin aynı anda çok amaçıı bir şekilde dizayn edildiği spor tesislerinde buna benzer bir ölçeğe rastlanamamıştır. Ölçeğin, spor tesislerinin mevcut yeterliği ile ilgili araştırmaların niteliğini artıracağı ve tesis inşa eden kamu ve yerel otoritelere de bir bakış açısı sunacağı öngörülmektedir.

\section{Kaynaklar}

Bergsgard, N. A., Borodulin, K., Fahlen, J., Hoyer-Kruse, J. Ve Iversen, E. B. (2017). National Structures for Building and Managing Sport Facilities: A Comparative Analysis of the Nordic Countries. Sport in Society, 22(4), 525-539.

Büyüköztürk, Ş. (2010). Sosyal Bilimler İçin Veri Analizi El Kitabı (11. Baskı). Ankara: Pegem Akademi.

Çokluk, Ö., Şekercioğlu, G. ve Büyüköztürk, Ş. (2010). Sosyal Bilimler İçin Çok Değişkenli İstatistik SPSS Ve LISREL Uygulamaları. Ankara: Pegem Akademi. Doğan, İ., Özdamar, K. (2017). The Effect Of Different Data Structures, Sample Sizes On Model Fit Measures. Communications in Statistics-Simulation and Computation, 46(9), 7525-7533. 
Földesi, G. S. (2014). The Impact of the Global Economic Crisis on Sport. Physical Culture and Sport Studies and Research, 63(1), 22-30.

Fried, G. (2010). Managing Sport Facilities. Human Kinetics.

Guo, X., Dai, J., Xun, P., Jamieson, L. M., ve He, K. (2014). Sport Facility Proximity and Physical Activity: Results from the Study of Community Sports in China. European Journal of Sport Science, 15(7), 663-669.

Hallmann, K., Wicker, P., Breuer, C. ve Schönherr, L. (2012). Understanding The Importance of Sport İnfrastructure for Participation in Different Sports Findings From Multi-Level Modelling. European Sport Management Quarterly, 12(5), 525-544.

Hoekman, R., Breedveld, K. ve Kraaykamp, G. (2015). A Landscape of Sport Facilities in the Netherlands. International Journal of Sport Policy and Politics, 8(2), 305-320.

Kline, R. B. (2005). Principles and Practice of Structural Equations Modelling. New York: Guilford.

Nicholson, M., Hoye, R. ve Houlihan, B. (2011). Participation in Sport: İnternational Policy Perspectives. Routledge.

Ries, A. V., Yan, A. F., ve Voorhees, C. C. (2011). The Neighbourhood Recreational Environment and Physical Activity Among Urban Youth: An Examination of Public and Private Recreational Facilities. Journal of Community Health, 36(4), 640-649.

Schumacker, R. E. ve Lomax, R. G. (2004). A Beginner's Guide to Structural Equation Modelling. New Jersey: Lawrence Erlbaum Ass.

Schwarz, E. C., Hall, S. A. ve Shibi, S. (2015). Sport Facility Operations Management: A Global Perspective. Routledge.

Stinnett, B., ve Gibson, F. (2016). Sustainable facility development: perceived benefits and challenges. International Journal of Sustainability in Higher Education, 17(5), 601-612.

Sugiyama, T., Francis, J., Middleton, N. J., Owen, N. ve Giles-Corti, B. (2010). Associations Between Recreational Walking and Attractiveness, Size, and Proximity of Neighbourhood Open Spaces. American Journal of Public Health, 100(9), 1752-1757.

Şimşek, Ö. F. (2007). Yapısal Eşitlik Modellemesine Giriş: Temel Ilkeler ve Lisrel Uygulamaları. Ankara: Ekinoks Yayıncılık. 
Çetin, A. ve karaçam, A. (2020). Spor Tesis Yeterliğini Belirlemeye Yönelik Bir Ölçek Geliştirme Çalışması. Gaziantep Üniversitesi Spor Bilimleri Dergisi, 5(3), 299-309.

Tabachnick, B. G., \& Fidell, L. S. (2007). Using Multivariate Statistics. Boston: Allyn and Bacon.

Westerbeek, H., Smith, A., Turner, P., Emery, P., Green, C. ve van Leeuwen, L. (2006). Managing Sport Facilities and Major Events. Routledge.

Yılmaz, V. ve Çelik, H. E. (2009). Lisrel Ile Yapısal Eşitlik Modellemesi-1. Ankara: Pegem Yayıncılık. 